\title{
Organics or not? Prospects for uptaking organic farming
}

\author{
Sotirios Papadopoulos*, Eleni Zafeiriou*, Christos Karelakis*, \\ TheOdoros Koutroumanidis*
}

DOI: $10.30682 / \mathrm{nm} 1801 \mathrm{~b}$

JEL codes: Q10, Q15, Q18

\begin{abstract}
Organic farming is the most widespread alternative form of agriculture, widely applied all around the world. Within the last few decades, the cultivation of organic products presented a rising trend, due to consumer preferences for safe products, produced by environmentally friendly procedures. The improvement and development of organic agriculture in the European Union was supported through various agrienvironmental programs of the Common Agricultural Policy. The present study surveys the producers' motivation for the adoption of organic farming, highlighting the most important ones. Primary data were obtained through a quantitative survey (structured questionnaire) to a sample of farmers from the region of Eastern Macedonia and Thrace and were analyzed via multivariate techniques, namely factor analysis and ANOVA. Results indicate that the farmer's decision to implement organic farming is determined by their attitude towards organic farming and to a lesser extent by economic reasons closely related to subsidies.
\end{abstract}

Keywords: Organic farming, Greece, CAP.

\section{Introduction}

Modern agriculture, in response to concerns about the viability and sustainability of the environment and product safety, has been accordingly adjusted to environmental issues (Lowe et al., 1997; Ward et al., 1998). This adjustment was achieved through agri-environmental subsidy programs (Morris and Potter, 1995; Wilson, 1997) and organic farming (Clunies-Ross and Cox, 1994; Tovey, 1997). Furthermore, societal environmental sensitivity along with the growing demand for safe and quality products led to the gradual conversion of conventional farming to alternative more environmentally oriented farming (Parra-Lopez et al., 2007a; Naspetti et all., 2016).
Organic farming is in accordance with an integrated management system, but in terms of philosophy the multi-dimensional concept including ecological and social values along with environmental criteria is the dominant one (Herring et al., 1991). The adoption of organic farming is based on different factors including socio-economic, agro-ecological, institutional, informational and psychological ( $\mathrm{Li}$ et al., 2014). Within the context of the CAP, various certification and direct payments schemes were selected to promote organic farming. Particularly, the 1992 CAP reform introduced the role of quality and food safety in agricultural products paving the way for organic agriculture. Subsequently, the Agenda 2000 that was entitled as the "New CAP"

\footnotetext{
* Democritus University of Thrace, Department of Agricultural Development, Orestiada, Greece. Corresponding author: sotpap23@gmail.com.
} 
intended to meet the increased market demand, to protect the environment (sustainable agriculture) and to improve the quality of product and food safety. Further, the legislative framework lately introduced by IFOAM EU (2014) involved the issue of: I) efficiency improvement in controls of European and third country operators; II) the trend towards a "100\% organic ingredients" approach (away from a "95\% approach"), limiting the list of non-organic ingredients to half in organic processing and improving origin labelling; III) the exceptional rules on reduction and transparency increasing in the regulation using a step-by-step approach; IV) the requirements introduction for measuring environmental performance by organic processors and traders; and V) the potential provision of certification to small farmers in Europe (in form of groups).

The EU holds the $26.6 \%$ of the total cultivated area with organics in the world, despite the different degree of organics uptaking among European countries (Willer and Lernoud, 2015). The highest level of adoption among the EU Member States is observed in Austria with $19.7 \%$ and Sweden with $15.4 \%$, followed by Estonia, Czech Republic and Latvia being above $10 \%$. Greece holds the $18^{\text {th }}$ place with $3.7 \%$, exhibiting an increasing trend since 2005. As regards cultivation areas, in Spain organic agriculture covers an area of 1.6 million Ha, exceeding Italy that is in the second and Germany that is $3^{\text {rd }}$ with an area of more than 1 million hectares. Greece holds the 10th place with 0.31 million hectares of organic farming, presenting a low growth rate $(7.3 \%)$ since 2005 .

The existing data on organic farming and the market in the EU are indicative of a well-developed organic sector with a steadily increasing growth rate despite the large discrepancies among the countries (Eurostat, 2013). In Greece the situation is in line with other EU countries in terms of production but not in terms of consumption. Implicitly, 23.433 organic producers have been recorded in Greece corresponding to $7 \%$ of all the producers in the EU and using $4 \%$ of the organic permanent cropland in EU for 2013 (Fibl and IFOAM, 2015).

Despite its continuous increase, organic farming is not sufficient by itself to demonstrate an environmentally friendly process, but should be both viable and manageable (Nardone et al., 2004). Evidently, any management system, being profitable, is not sustainable (Edwards et al., 2001). Considering the aforementioned, the present study surveys the factors that determine the farmer's decision to adopt organic agriculture. The study was based on primary data, collected through personal interviews (questionnaires) to farmers in the region of Eastern Macedonia and Thrace (Greece). The remainder of the paper includes the review of extant literature in section 2, followed by a description of the material and methods employed. Section 4 presents the results of the data processing followed by their discussion on section 5 . The final section concludes.

\section{Literature Review}

The organic farming and especially the agro-environmental and economic impacts of the uptaking of this type of management compared to that of conventional management has been a subject of study with different methodologies. Binta and Barbier (2015), in their study used the gross margin as an economic indicator, and carbon emissions as environmental indicator. Their results provide evidence that in financial terms organic farming is more attractive to farmers in the particular research area compared to the conventional farming system only when a premium price is applied to organic crops. Furthermore, the simulation results also reveal a "win-win" situation for conventional farmers when uptaking organic farming for specific crop types. On the other hand, environmental impacts based on carbon emissions reduction confirm that organic system is found a more effective management system in mitigating climate change.

Forster et al. (2013), studied the yield and economic performance of organic and conventional cotton based farming system in terms of an experimental plot. According to their findings not only higher yield but also better economic performance can be achieved with less capital intensive farming systems. Though, these results are feasible when farmers do not confront impediments including market access, access to inputs and know-how, while particular costs are associated with the organic certification process.

Though, the economic performance and the financial motivation are not always the determinants for the uptaking of organic farming. The attitude of farmers towards organic farming or even the rea- 
sons for which they decide to convert to organic farming is a complex task and has been a subject of extensive survey with different methodologies. Darnhofer et al. (2016) with the assistance of a decision tree and based on 21 interviews with farmers intended to provide an insight to the rationale that motivates the behavior, revealing also the decision criteria as well as the decision making process of the farmers in the sample. Furthermore, five types of farmers were identified as follows; the "committed conventional"; the "pragmatic conventional"; the "environment-conscious but not organic"; the "pragmatic organic"; and the "committed organic". The accuracy of the decision-tree was tested through a written survey of 65 randomly sampled farmers. An issue also worth mentioning is the fact that it takes into consideration the heterogeneity in farmers' attitudes, their preferences, their goals and their impact on the selection of the farming method.

In another study, Tey et al. (2013) surveyed the role of different factors in decision making for adopting sustainable management practices. According to their findings, with the assistance of a logistic regression they found that the reasons for adoption of sustainable practices, are socio - economic agro - ecological institutional, informational and psychological. Though, this result concerns only the agriculture in Malaysia.

With the assistance of a different methodology is surveyed the decision making process by the Irish farmers to adopt organic farming (Läpple and Keelly, 2013). This study is based on the theory of planned behavior regarding the control of social influence and technical constraints. To be specific, Cluster analysis and principal component analysis are employed to account for sample heterogeneity and to identify heterogeneities in farmer attitude towards adoption of organic farming. According to their findings, the impact of economic incentives and technical barriers seem to be asymmetric, while social acceptance of organic farming seem to be vital in organic farming uptaking. The particular findings are indicative of limited efficiency of increase in the organic sector given the existence of social and technical barriers.

Beyond the existing literature focusing on the concepts and psychological reasons identified a limited literature has arisen aiming to detect the causality among the demographic features and en- vironmental behaviour. To be more specific, Barton (2014) tried to relate environmental behavior to specific demographic features including age, experience, education, and gender for assumed causal links. According to his findings based on the existing literature he concluded that the issue of causality is a complex one. Scheme deterministic factors for this causality can be mentioned inadequately specified measurements of demographic characteristics, the treatment of non-linear causalities as linear and others. Furthermore, demographic characteristics are considered to be affected (in different extend) by cultural-historical patterns which in turn establish differences in the relationship with environmental behaviour.

Having in mind all the above, the present manuscript makes an effort to identify demographic features and other determinants of the behavior of farmers in Anatoliki Macedonia and Thraki towards organic farming within the CAP regime promoting organic farming through different policy measures.

\section{Materials and Methods}

The questionnaires through which primary data were collected had as research area six Regional Districts (Serres, Drama, Kavala, Xanthi, Rodopi and Evros) of Anatoliki Macedonia and Thraki in Greece. The sample includes farm leaders adopting either conventional or organic farming for the year of research. Per the statistical data from the Ministry of Development and Food, the Payment and Control Agency for Guidance and Guarantee Community Aid (OPEKEPE) and the Hellenic Agricultural Organization "Dimittra" (previously known as the National Agricultural Research Foundation), the research area includes all cultivation types ( organic and conventional agriculture) covering $20 \%$ of farms in Greece. 871 organic agriculture farms are included in the research area (a total of 6,494 hectares). Thus, the study includes 162,684 cultivation units corresponding to 340,000 hectares. Within this region we identified nine farming types of integrated agriculture. All the aforementioned farming types are members of the conventional group.

The methodology of stratified random sampling implies a division of the whole heterogeneous population into smaller groups or subpopulations, in order the sampling units to be homogeneous with 
respect to the feature under review within the subpopulation while heterogeneity is valid concerning the characteristic under study between/among the subpopulations named as strata. Each subpopulation should be treated as a separate population and the sample drawn from each stratum was Simple Random Sampling (SRS) (Siardos, 2009). The selection of sample sizes within the strata is based on the variability minimization, therefore subgroups are identified through Neyman or optimum allocation. SRS is applied within each stratum; thus, the final sample size was the sum of the samples of the generated strata. Implicitly, the required information from each stratum has been accurate. Given that the basis of stratification consists of variables directly connected to the key variables for the research (Daoutopoulos, 2011), as "stratum" is set the farming type of each form of agriculture. Therefore, the sample size was estimated by the following formula:

$$
n=\frac{\left(\Sigma N_{h} s_{h}\right)^{2}}{N^{2} D^{2}+\Sigma N_{h} s_{h}^{2}}
$$

The sampling units in every stratum is provided by the following formula;

$$
n_{h}=\frac{N_{h} s_{h}}{\sum N_{h} s_{h}} \cdot n
$$

where $\mathrm{D}$ denotes the accepted standard error given by $\mathrm{D}=\mathrm{d} / \mathrm{z}$ (where $\mathrm{d}=$ the desired accuracy [equal to half of the confidence interval or subjects specified] and $\mathrm{z}$ denotes the reliability coefficient corresponding to a probability level). The term $\mathrm{s}_{\mathrm{h}}$ denotes the typical deviation value of farm size in each stratum the calculation of which is based on farm population data. $\mathrm{N}_{\mathrm{h}}$ is the size sampling of each stratum, and $\mathrm{N}$ denotes the total sample size.

Prior to the quantitative part of the study a qualitative (pilot) research was conducted in order to test the questionnaire using a smaller sample compared to the planned sample size. This questionnaire is administered to a percentage of the total sample population (Creswell, 1998). For our case within the qualitative phase, farmers were interviewed using a semi-structured questionnaire consisted of 14 thematic units. A direct-sampling method was used to ensure more information of high significance to be collected (Patton, 1990). Thus, 42 farmers were identified (equal to the $10 \%$ of the total population) and agreed to be interviewed. These interviews were recorded. During the subsequent quantitative phase, a survey was conducted using a uniform questionnaire. The questionnaire included three sets of questions while its structure was based on prior existing literature (Siardos, 2009). The first part included questions concerning both demographic and personal data of farm leaders (e.g., sex, age, family status, origin and education) as well as the farmers' relationships with organized groups and potential participation into subsidized programs. The second unit referred to the general farm characteristics (e.g., form of exercised agriculture, disposal, certification type and subsidy type), such as business gains, as well as issues concerning the methods and farmers' satisfaction with CAP reforms. The third unit involved questions aiming to derive data on the positions of farmers towards the CAP and in particular towards factors affecting the application of organic, integrated and conventional agriculture. Finally, information concerning the farmers' intentions on the adoption of a specific type of agriculture as well as the determinants of conserving or abandoning this type.

\subsection{Methodological approach}

Initially with the assistance of descriptive statistics the most important characteristics of the farmers and farms types have been identified. To be more specific we calculated the frequencies in each category, being provided by frequency tables. Secondly, a one-way analysis of variance was implemented in order to verify whether a single variable differs significantly among three or more levels. The particular analysis is appropriate for a single factor with three or more levels and multiple observations at each level through which we calculate the mean of the observations within each level of the factor. Explicitly, the null hypothesis to be tested is the following:

$$
H_{0}: \mu_{1}=\mu_{2}=\ldots=\mu_{n}
$$

While the alternative hypothesis is the following; $H_{\mathrm{a}}\left\{\right.$ Does not apply the $\left.H_{0}\right\}$ 
Prior to the implementation of the aforementioned test a few assumptions have been tested including;

1. Each sample is drawn from a normal distribution population. Within each sample, the observations are sampled randomly.

2. Independency of the samples is ensured.

3. No heteroscedasticity problems should be detected.

The analysis of variance is quite robust in the case of small samples and unequal deviations within the groups (Field, 2009); therefore, in a study where a serious violation of the assumptions is confirmed, an alternative non-parametric analysis of variance is employed. The non-parametric techniques, do not require the validity of conditions for the distribution of the dependent variable since data classification is employed (ranking). In the present study, the Kruskal-Wallis test a non-parametric method is used since no assumptions about the type of underlying distribution are needed to be made.

\section{Results}

Out of the 122 organic farmers questioned, $85.2 \%$ were male and the $14.8 \%$ were female. Among the 150 conventional agriculture farmers surveyed, the $88.7 \%$ were male and $11.3 \%$ were female. Most of the farmers were aged between 35 and 55 . The proportion of organic farmers fell within this age range $(50 \%)$, whereas this value was significantly higher $(63.3 \%)$ for those of the conventional ones. These findings are in line with previous research indicating that the majority of farmers are middle-aged (Theocharopoulos, 2009). Fourteen percent of conventional agriculture farmers was single, while this value was $19.7 \%$ for organic farmers. Almost all farmers in the sample have acquired some form of secondary education. Only $2.5 \%$ of the organic farmers were graduates of higher education. None of the conventional agriculture farmers had attended a relevant training seminar, whereas almost a third of the farmers applying organic agriculture had attended a relevant training seminar (Table 1).

Table 1 - Demographic characteristics of farmers.

\begin{tabular}{|c|c|c|c|c|c|}
\hline \multicolumn{2}{|l|}{ Factors } & \multicolumn{2}{|c|}{ Organics } & \multicolumn{2}{|c|}{ Conventional } \\
\hline & & \multirow{2}{*}{$\begin{array}{c}\text { Frequency } \\
104\end{array}$} & \multirow{2}{*}{$\begin{array}{c}\text { Percent } \\
85.2\end{array}$} & \multirow{2}{*}{$\begin{array}{c}\text { Frequency } \\
133 \\
\end{array}$} & \multirow{2}{*}{$\begin{array}{c}\text { Percent } \\
88.7\end{array}$} \\
\hline Gene & Men & & & & \\
\hline & Women & 18 & 14.8 & 17 & 11.3 \\
\hline \multirow[t]{3}{*}{ Age } & $<35$ & 48 & 39.3 & 35 & 23.3 \\
\hline & $36-55$ & 61 & 50 & 95 & 63.3 \\
\hline & $>55$ & 13 & 10.7 & 20 & 13.3 \\
\hline \multirow[t]{4}{*}{ Marital status } & Unmarried & 24 & 19.7 & 21 & 14 \\
\hline & Married & 93 & 76.2 & 111 & 74 \\
\hline & Divorced & 5 & 4.1 & 9 & 6 \\
\hline & Widower & 0 & 0 & 9 & 6 \\
\hline \multirow[t]{5}{*}{ Education } & Primary school & 12 & 9.8 & 10 & 6.7 \\
\hline & Secondary school & 40 & 32.8 & 76 & 50.7 \\
\hline & High school & 36 & 29.5 & 51 & 34 \\
\hline & Technical school & 31 & 25.4 & 13 & 8.7 \\
\hline & University & 3 & 2.5 & 0 & 0 \\
\hline \multirow[t]{2}{*}{ Seminar Attendance } & Yes & 44 & 36.1 & 6 & 4 \\
\hline & No & 78 & 63.9 & 144 & 96 \\
\hline
\end{tabular}


Three quarters of the producers in the survey, for both forms of agriculture, is married and unmarried is $19.7 \%$ of organic farmers and $14 \%$ of the manufacturers of conventional agriculture. Meanwhile, $56 \%$ of conventional agriculture producers have two children, while this rate drops to $45 \%$ in organic agriculture. The greatest percentage of minor children included in organic agriculture $(35.2 \%)$, while the $32 \%$ of conventional producers have minor and adult children. Twice as many organic farmers were new farmers (i.e., $<5$ years of agriculture experience) than for conventional agriculture farmers, which is consistent with our finding that organic farmers tend to be younger than the conventional type of farmers. $30 \%$ of conventional agriculture farmers concluded that agriculture was their only available career option. While this value is $39.3 \%$ for organic agriculture farmers. The whole people who engaged in conventional farming have attended a training course, while one third of farmers concerned with organic farming, has attended some training on organic management. Noteworthy is the fact that the large proportion of certified producers of organic sample, sell their products as conventional ones. Finally, in the sample of conventional agriculture, no producer was found to have been organic farmer in the past. For that reason, the research was limited to study the reasons of joining the organic farming.

\subsection{Motives for adopting Organic Farming}

The one-way analysis of variance was used to determine whether there are significant differences between the seven reasons phrased that a producer prefers to be certified under Organic protocol as well as the identification of these differences and which are the most important. In this case, a non-parametric one-way analysis of variance was set because the basic conditions of parametric ANOVA, such as the homogeneity of variances and the normal distribution are not being met. The analysis as it emerged from the Kruskal-Wallis test is significant at $5 \%$ of significance level $\left(\mathrm{x}^{2}=509.683 \mathrm{df}=6, \mathrm{p}\right.$-value $\left.<0.05\right)$. There and are differences among the reasons that one considers for joining organic farming (Table 2).
Table 2 - Good fit of the analysis of variance model for inclusion in organic farming.

\begin{tabular}{|c|c|}
\hline \multicolumn{2}{|c|}{ Test Statistics ${ }^{\mathrm{a}, \mathrm{b}}$} \\
\hline & Joining Organic Farming \\
\hline Chi-Square & 509.683 \\
\hline $\mathrm{df}$ & 6 \\
\hline Asymp. Sig. & 0.000 \\
\hline${ }^{\mathrm{a}}$ Kruskal Wallis Test \\
\hline${ }^{\mathrm{b}}$ Grouping Variable: Reasons \\
\hline
\end{tabular}

Table 3 - Average ranking indicators of inclusion criteria in organic farming.

\begin{tabular}{|l|c|c|}
\hline \multicolumn{3}{|c|}{ Ranks } \\
\hline Reasons & $\mathrm{N}$ & Mean Rank \\
\hline Better availability of products & 122 & 499.49 \\
\hline Subsidy purposes & 122 & 275.25 \\
\hline Ideological reasons & 122 & 210.20 \\
\hline Improving the quality/safety & 122 & 316.77 \\
\hline Environmental reasons & 122 & 308.08 \\
\hline Market requirement & 122 & 668.86 \\
\hline Best financial result & 122 & 713.86 \\
\hline Total & 854 & \\
\hline
\end{tabular}

The mean ranks (Table 3) validated the fact that all the reasons affecting the adopting of Agro certification are different (Fig. 2), while the Sample averages and standard deviations for each of the seven reasons are presented in the next Table 4.

In terms of importance, the non personal values or alternatively ideological reasons seem to dominate in the farmers decision to uptake organic farming. The role of subsidies seems to be in the second position while the environmental attitude of the farmers is following. The impact of organic farming on the quality and safety products improvement is a moderate weight criterion in adoption of organic farming, the products availability the adjustment to the market demand and purely financial reasons is the rest of ranking situation among the rest of the motivations according to the views of the farmers in North Eastern Macedonia.

The next Figure 1 illustrates the mean ranks criteria for joining organic farming. 
Table 4 - Sample averages and standard deviations of the inclusion criteria for organic farming.

\begin{tabular}{|c|c|c|c|c|c|c|c|c|}
\hline \multicolumn{9}{|c|}{ Descriptives } \\
\hline \multirow{2}{*}{ Reasons } & \multirow{2}{*}{$\mathrm{N}$} & \multirow{2}{*}{ Mean } & \multirow{2}{*}{$\begin{array}{c}\text { Std. } \\
\text { Deviation }\end{array}$} & \multirow{2}{*}{$\begin{array}{l}\text { Std. } \\
\text { Error }\end{array}$} & \multicolumn{2}{|c|}{$\begin{array}{l}95 \% \text { Confidence } \\
\text { Interval for Mean }\end{array}$} & \multirow{2}{*}{ Minimum } & \multirow{2}{*}{ Maximum } \\
\hline & & & & & $\begin{array}{l}\text { Lower } \\
\text { Bound }\end{array}$ & $\begin{array}{l}\text { Upper } \\
\text { Bound }\end{array}$ & & \\
\hline $\begin{array}{l}\text { Better availability } \\
\text { of products }\end{array}$ & 122 & 3.1066 & 0.82128 & 0.07436 & 2.9594 & 3.2538 & 1.00 & 4.00 \\
\hline Subsidy purposes & 122 & 1.9672 & 1.10547 & 0.10008 & 1.7691 & 2.1654 & 1.00 & 5.00 \\
\hline Ideological reasons & 122 & 1.6148 & 0.60911 & 0.05515 & 1.5056 & 1.7239 & 1.00 & 3.00 \\
\hline $\begin{array}{l}\text { Inproving the quality/ } \\
\text { safety }\end{array}$ & 122 & 2.1311 & 0.72671 & 0.06579 & 2.0009 & 2.2614 & 1.00 & 3.00 \\
\hline Environmental reasons & 122 & 2.0984 & 0.75416 & 0.06828 & 1.9632 & 2.2335 & 1.00 & 4.00 \\
\hline Market requirement & 122 & 4.2377 & 1.06059 & 0.09602 & 4.0476 & 4.4278 & 1.00 & 5.00 \\
\hline Best financial result & 122 & 4.4918 & 0.63306 & 0.05731 & 4.3783 & 4.6053 & 3.00 & 5.00 \\
\hline Total & 854 & 2.8068 & 1.35888 & 0.04650 & 2.7155 & 2.8981 & 1.00 & 5.00 \\
\hline
\end{tabular}

Figure 1 - Mean ranks of criteria for joining organic farming

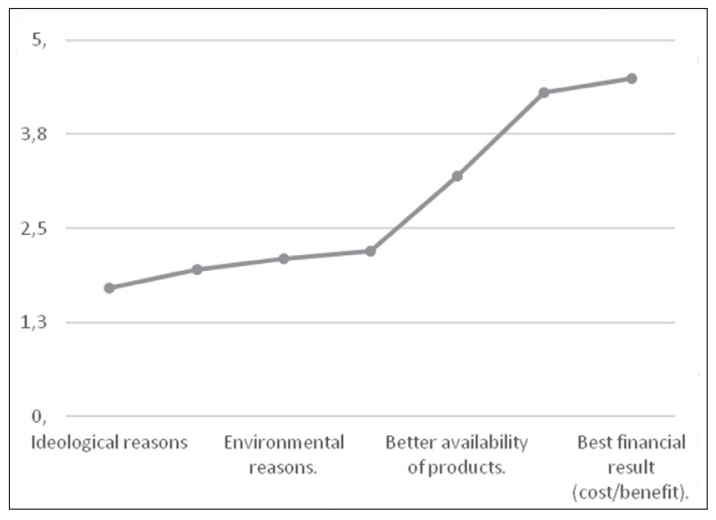

\section{Discussion of the results}

The present work is an effort to identify the demographic features and the motivating factors of the farmers to adopt organic farming for the region of Anatoliki Macedonia and Thraki, in Greece. Regarding the demographic features of the respondents the high percentage of young farmers adopting organic farming is an expected result given the innovations needed to be employed in terms of farming practices as well as the concept of organic farming in general. Furthermore, the higher education level and the seminar attendance is a feature of organic farmers, given that these are a pre-condition for efficient and profitable organic farming compared to those adopt conventional farming.

Regarding the determinants of organic farming, the personal values have been identified as the most important factor for producers to adopt organic farming for their farms, a result that is in line with Darnhofer et al. (2015). This concept has dominated the farmers behavior recently since in previous studies, , it has been found that producers' intention to convert their farming system from conventional to organic is primarily based on economic rather than ideological motives (Bluckmeier et al., 1994; Fairweather and Campbell, 1996). Subsidies are the second most important reason for joining the organic farming, because the existence or lack of subsidies respectively may well lead to an increase or reduction of the covered area and the number of organic holdings. Similarly, at European level, the development of organic agriculture is assisted by the various policies of the EU interventions (Stolze and Lampkin, 2009).

The environmental attitude consist a significant determinant in the uptake of organic farming a result that is in line with that of Läpple and Rahsburg (2011). Implicitly, the environmental attitude appears to play a complementary role on the producers' decision to deal with this form of agriculture (Theocharopoulos, 2009; Papadopoulou et 
al., 2008). Though the particular results does not give us with an insight on the farmers understanding of biodiversity or the practical measures taken to enhance the adoption of agri - environmental schemes by farmers. This is an observed result recorded by Herzon and Mikk (2007) for farmers in Finland.

The same level of importance is given to improve the quality of their products as it seems to be perceived by producers as part of their ideological view about organic farming. Also, the improvement of the quality is associated with the demands of consumers for safe and certified food. These findings are similar to the factors of adoption of ICM in England (Park et al., 1997).

The producers do not consider that the better availability of organic products is an important factor that will lead to their involvement in organic agriculture. As noted in the descriptive analysis of the survey data, existing producers in their majority do not sell their products as organic. Therefore, these producers do not consider the demand of the market for organic products as an important reason, and find that they do not achieve better financial results in organic management compared with other forms of agriculture.

Theoharopoulos in 2009 argued similar results, drawing data on 2004 and from a particular crop, which prioritizes in the first category the quality improvement, the environmental protection and the ideological reasons, while a second category includes the subsidy reasons. But as it is marked by the same researcher, the producers seem to understate their answers on the role of the various subsidies and incentives they receive for their entrance in organic farming. It should be noted that this survey was conducted in 2012, a period in which the subsidy program for organic farming was not effective and respondents were producers who remained in organic management without being subsidized. This shows that in addition to subsidies, there are other important factors, such as ideological and environmental reasons and reasons of quality products, which significantly influence the decision of a producer joining organic management system.

The questioning developed through extensive implementation of conventional agriculture, both for its impact on the environment and the quali- ty of agricultural products (Lobstein, 1999; Sundrum, 2001), led to the creation of new forms of alternative agriculture, mainly represented by the biological and integrated agriculture.

Within the European Union, the Regulation No 2092/91 initiated a substantive development of organic farming, which continued with several modifications. Certainly, the systematic support measures for the quality and safety of agricultural products starts from the reform of the MacSharry in 1992, with the main station the New CAP Fischler reform in 2003, which provided incentives to enable various forms of alternative agriculture (Carbone and Sorrentino, 2006). Organic farming is the most sustainable methods of producing safe for consumption agricultural products. According to pertinent existing literature the adoption of organic farming relies mainly on environmental consciousness and ideology producer (Willer and Gillmour, 1992; Fairweather, 1999; Duram, 2000; Storstad and Bjorkhaug, 2003). Yet the ideology faded, especially after the inclusion of organic farming in the modern economic system (Rigby and Caceres, 2001). More recent studies support the view that the significant development of organic agriculture is assisted by various policies of the EU interventions and financial incentives provided by the existing CAP regime (Tzouramani et al., 2009; Stolze and Lampkin, 2009; Offermann et al., 2009). The last CAP reform in 2003, seems to be able to support the continued positive development of organic agriculture (Haring and Offermann, 2005). Especially, from 2014 and onwards, within the greener CAP more measures are taken to promote the adoption of organic farming. Implicitly $30 \%$ of the rural development programmes' budget have to be dedicated to agri-environmental measures, securing support for organic farming or projects associated with environmentally friendly investment or innovation measures. The currently available data indicate that organic agriculture, although showing an upward trend, failed to prevail neither in Greek nor in Europe and worldwide (FiBL-Global Organic Statistic and News, 2011). The causes of this phenomenon could indicate the viability of organic farms (Nardone et al., 2004). While 30$40 \%$ reduced yields of organic agriculture compared with conventional (Nieberg and Offermann, 
2003), may raise food problem, because of the growing population of the earth. However, there are countries worldwide, including Australia and Argentina and at European level, such as Austria and Sweden showing particularly high growth of organic farming (http://www.organic-world.net).

\section{Conclusions}

The present research aimed to highlight the significant factors leading farmers to adopt organic farming. We found that the most important factor affecting this producers' decision are own ethical values while technical issues on agricultural production and farm structure is an issue of high importance for potential organic farmers. Furthermore, financial reasons including the amount of subsidies is less pivotal, while the environmental friendly behavior provides also a motivation for the adoption of organic farming.

Therefore, the promotion of organic farming can become a successful mission under specific conditions. As mentioned above given that the criteria for conversion are identified and furthermore features of specific farmers are found, strategies and policies implemented accordingly within CAP regime along with national policies would lead to the desired goal of adopting organic management practices. A critical condition that a policy implemented should satisfy, in order to be successful is a combination of non economic benefits to profitability leading to eco-efficiency (Tey et al., 2013; Li et al., 2014). To synopsize, the policy tools should be adjusted to the farming rationale of the farmers in order the advantages of organic farming beyond the financial ones to be mediated to them successfully.

\section{References}

Ahner D. and Scheele M., 2000, "The Common Agricultural Policy: An overview from where we come, where we are, Tasks ahead", paper presented at the International Postgraduate Course on "European Agricultural Policy in Transformation", Wageningen University, 15 September 2000.

Binta B.A. and Barbier B., 2015. Economic and Environmental Performances of Organic Farming System Compared to Conventional Farming System: A Case
Study of the Horticulture Sector in the Niayes Region of Senegal. Procedia Environmental Sciences, 29: 1719.

Bluckmeier K., Grund H., Symes D. and Jansen A.J., 1994. Perspectives and environmentally sound agriculture in east Germany. Agricultural Restructuring and Rural Change in Europe, 37: 180-194.

Burton R.J. 2014. The influence of farmer demographic characteristics on environmental behavior: A review. Journal of environmental management, 135: 19-26.

Carbone A. and Sorrentino, A. 2006. "The European Policy for Food Quality and the Fischler's Reform". Università della Tuscia, Viterbo, Italy. Paper prepared for presentation at the 99th EAAE Seminar "Trust and Risk in Business Networks", Bonn, Germany, February 8-10, 2006.

Clunies-Ross T., Cox G., 1994. Challenging the productivist paradigm: organic farming and the politics of agricultural change. In: Lowe P., Marsden T., Whatmore S. (eds.), Regulating Agriculture. London: David Fulton, 53-75.

Creswell J.W., 1998. Qualitative Inquiry and Research Design: Choosing among Five Traditions. London and Thousand Oaks, CA: Sage Publications.

Darnhofer I., Schneeberger W. and Freyer B., 2015. Converting or not converting to organic farming in Austria: Farmer types and their rationale. Agriculture and Human Values, 22.1(2005): 39-52.

Duram L.A., 2000. Agents' perceptions of structure: How Illinois organic farmers view political, economic, social and ecological factors. Agriculture and $\mathrm{Hu}$ man Values, 17: 35-48.

Fairweather J.R., 1999. Understanding how farmers choose between organic and conventional production: Results from New Zealand and policy implications. Agriculture and Human Values, 16: 51-63.

Field A., 2009. Discovering Statistics Using SPSS, $3^{\text {rd }}$ Edition, London and Thousand Oaks, CA: Sage Publications.

Forster D., Andres C., Verma R., Zundel C., Messmer M.M., and Mäder P., 2013. Yield and economic performance of organic and conventional cotton-based farming systems-results from a field trial in India. PloS one, 8(12), e81039.

Granatstein D., 2000. Alternative Markets for Fruit: Organic and IFP. Proceedings of the 16th Annual Postharvest Conference, Yakima, WA, 14-15 March. Available at: http://postharvest.tfrec.wsu.edu/pgDisplay.php?article $=\mathrm{PC} 2000 \mathrm{M}$.

Häring A.M. and Offermann F., 2005. Impact of the EU Common Agricultural Policy on organic in comparison to conventional farms. XIth International Congress of the EAAE. The Future of Rural Europe in the 
Global Agri-Food System. Copenhagen, Denmark, August 24-27, 2005.

Henning J., Baker L. and Thomassin P.J., 1991, Economics issues in organic agriculture, Canadian Journal of Agricultural Economics, 39: 877-889.

Läpple D. and Kelley H., 2013. Understanding the uptake of organic farming: Accounting for heterogeneities among Irish farmers. Ecological Economics, 88: 11-19.

Läpple D. and Van Rensburg T., 2011. Adoption of organic farming: Are there differences between early and late adoption? Ecological economics, 70(7): 1406-1414.

Lobstein T., 1999. Why Consumers Have Lost Confidence in the Food Industry, International Food Safety Handbook: Science, International Regulation and Control (AA. VV. Eds), Marcel Dekker, Inc. New York.

Loureiro M.L., McCluskey J.J., and Mittelhammer R.C., 2000. Consumer response and willingness to pay for sustainable agriculture products. Selected paper presented at the 2000 American Agricultural Economics Association meetings, Tampa, Florida, USA.

Morris C., Potter C., 1995. Recruiting the new conservationists: farmers' adoption of agri-environmental schemes in the UK. Journal of Rural Studies, 11: 51-63.

Nardone A., Zevras G. and Ronchi B., 2004. Sustainability of small ruminant organic systems of production, Livestock Production Science, 90: 27-39.

Naspetti S., Bteich M.R., Pugliese P., Salame N., 2016. Motivation and values of farmers in Lebanon: a comparison between organic and conventional agricultural producers. New Medit, 15(2): 70-80.

Nieberg H. and Offermann F., 2003. The profitability of organic farming in Europe. 141-153. In OECD: Organic Agriculture: sustainability, markets and policies. CAB Publishing, UK.

Offermann F., Nieberg H., Zander K., 2009. Dependency of organic farms on direct payments in selected EU member states: Today and tomorrow. Food Policy, 34: 273-279.

Papadopoulou E., Nastia S., and Pappas A., 2008. Cooperatives, integrated production management and environment: The case of Imathia. Geotechnical Scientific Issues, 19 (3): 32-42.

Park J., Farmer D.P., Bailey A.P., Keatinge J.D.H., Rehman T., Tranter R.B., 1997. Integrated arable farming systems and their potential uptake in the UK. Farm Management, 9(10): 483-494.
Parra López C.; Calatrava Requena J.; De Haro Giménez T., 2007a. A multi-criteria evaluation of the environmental performances of conventional, organic and integrated olive-growing systems in the south of Spain based on experts' knowledge. Renewable Agriculture and Food Systems, 22(3): 189-203.

Patton M.Q., 1990. Qualitative evaluation methods $\left(2^{\text {nd }}\right.$ ed.), Thousand Oaks, CA: Sage.

Rigby D. and Caceres D., 2001. Organic farming and the sustainability of agricultural systems. Agricultural systems, 68: 21-40.

Siardos G.K., 2009. Methodology of Sociological Research. Zitis Publications.

Stolze M. and Lampkin N., 2009. Policy for organic farming: Rationale and concepts. Food Policy, 34: 237-244.

Storstag O. and Bjorkhaug H., 2003. Foundation of production and consumption of organic food in Norway: Common attitudes among farmers and consumers. Agriculture and Human Values, 20(2): 151-163.

Sundrum A., 2001. Organic livestock farming - A critical review. Livestock Production Science, 67(3): 207-215.

Theocharopoulos A., 2009, Economic and environmental analysis of alternative forms of agriculture. Doctoral Thesis. Department of Agricultural Economics. School of Agriculture, Aristotle University of Thessaloniki.

Tey Y.S., Li E., Bruwer J., Abdullah A.M., Brindal M., Radam A., Ismail M.M. and Darham S., 2014. The relative importance of factors influencing the adoption of sustainable agricultural practices: a factor approach for Malaysian vegetable farmers. Sustainability science, 9(1): 17-29.

Tovey H., 1997. Food, environmentalism and rural sociology on the organic farming movement in Ireland. Sociologia Ruralis, 37: 21-37.

Tzouramani I., Liontakis A., Sintori A., and Alexopoulos G., 2009. Policy implementations for organic agriculture: A real options approach. The $83^{\text {rd }}$ Annual Conference of the Agricultural Economics Society. Dublin. 30 ${ }^{\text {th }}$ March to $1^{\text {st }}$ April 2009.

Willer H. and Gillmour D.A., 1992. Organic agriculture in the Republic of Ireland. Irish Geography, 25(2): 149-159.

Wilson G.A., 1997. Factors influencing farmer participation in the Environmentally Sensitive Areas scheme. Journal of Environmental Management, 50: 67-93. 